\title{
Atomic Level Characterization of Neutron Irradiated Pressure Vessel Steels
}

\author{
M. K. Miller ${ }^{1}$ and P. Pareige ${ }^{2}$ \\ ${ }^{1}$ Metals and Ceramics Division, Oak Ridge National Laboratory, Oak Ridge, TN 37831-6136 \\ ${ }^{2}$ Groupe de Physique des Matériaux, Equipe de Recherche Technologique,UMR CNRS 6634, \\ Faculté des Sciences et INSA de Rouen, 76821 Mont Saint Aignan Cedex, France
}

\begin{abstract}
Atom probe tomography provides one of the most effective tools to characterize the solute distribution and precipitation that occurs in pressure vessel steels and associated model alloys during irradiation. The three-dimensional atom probe is able to experimentally determine the elemental identities of the atoms and their spatial coordinates with near atomic resolution so that their distribution within small volumes of the specimen can be reconstructed and analyzed. This technique together with conventional atom probe field ion microscopy has been applied to many different types of pressure vessel steels and model alloys and has revealed and characterized several different nanostructural transformations. These radiation induced or enhanced processes lead to the formation of copper-nickel-manganese-silicon precipitates, and solute segregation to dislocations, dislocation loops, nanovoids and boundaries.
\end{abstract}

\section{INTRODUCTION}

The mechanical properties of the pressure vessel steels that are used in nuclear reactors can change dramatically during service due to the interaction of the solutes in the vessel with the vacancies and other products created by the incident neutrons. It is therefore important to be able to accurately characterize the microstructure and correlate the changes that occur during the initial processing of the steel and service with the mechanical properties. Many diverse techniques have been used to characterize the microstructure of these steels and related model alloys. Two of the most powerful techniques are atom probe field ion microscopy (APFIM) $[1,2]$ and atom probe tomography (APT) [3,4]. Both of these techniques provide information on the redistribution of solute including solute segregation to dislocations and boundaries, and precipitation on the atomic scale. Many applications of these techniques have been performed on a variety of different reactor pressure vessel (RPV) steels and the results have been reviewed $[5,6]$. These atom probe studies established that a high density of ultra-fine copper-, manganese-, nickel- and silicon-enriched precipitates form during neutron irradiation. These studies have also documented the size and compositions of some of the coarse precipitates including cementite, $\mathrm{Mo}_{2} \mathrm{C}$ and vanadium carbonitrides precipitates that are present in various steels and model alloys.

\section{ATOM PROBE TOMOGRAPHY}

In both APFIM and APT techniques, atoms are field ionized and field evaporated from a needle-shaped specimen by the application of a high voltage pulse superimposed on a standing voltage. The flight times to a single atom sensitive detector at the end of a time-of-flight mass spectrometer are measured. The mass-to-charge ratio of the ions and hence their elemental identities are determined from the equivalence of the potential energy of the atom on the surface of the specimen prior to field evaporation with the kinetic energy that is acquired after the ion 
leaves the surface. Most modern instruments feature sufficient mass resolving power to separate the individual isotopes of all elements. The local composition is determined by counting the number of atoms of each element within a volume. The atom probe field ion microscope incorporates a small entrance aperture in the mass spectrometer to define the area of analysis. Therefore, atoms that were contained in a small diameter cylinder in the specimen are analyzed. In the three-dimensional atom probe (3DAP), the area of analysis is defined by the effective size of single atom position-sensitive detector at the end of the mass spectrometer. The resulting volume of analysis may contain up to a few million atoms and typically has a square cross section that is 10 to $20 \mathrm{~nm}$ in extent and is up to $250 \mathrm{~nm}$ long. The spatial coordinates of each atom in that volume are determined from its impact position on the detector ( $\mathrm{x}$ and $\mathrm{y}$ ) and its position in the evaporation sequence $(\mathrm{z})$. These data may be visualized and analyzed after the experiment to detect and quantify variations in the local compositions due to precipitation and solute segregation $[3,4]$.

The size of features, such as precipitates or clusters, may be estimated with APT by several methods including counting the number of atoms contained within the feature, or estimating its extent in either atom maps or isoconcentration surfaces. A more accurate method is to calculate the radius of gyration, $1_{\mathrm{g}}$, and Guinier radius from the positions of the atoms in a precipitate $[3,7]$. In order to perform this calculation, the atoms associated with the feature of interest have to be defined. The procedure that is used is to assign to that precipitate all the atoms of one or more selected solute element that are within a specific distance of similar atoms within the volume of analysis. An advantage of the radius of gyration measurement is that it may be compared directly with the same parameter estimated from small angle neutron scattering (SANS) measurements. The number density of precipitates is estimated independently from the number of precipitates in the analyzed volume. The phase identity is generally inferred from its composition, which is determined from the number of atoms of each element present in the feature.

\section{APT CHARACTERIZATION OF PRESSURE VESSEL STEELS}

Irradiation damage in RPV steels is commonly comprised of three main components: matrix damage, embrittlement due to the presence of precipitates and other types of solute enriched regions, and non hardening embrittlement. Precipitation is the most important factor and most experimental studies have focussed on its characterization. The results of some recent atom probe tomography investigations of the microstructural changes that occur in RPV steels during thermal ageing, neutron irradiation, annealing and re-irradiation are reviewed in this section.

\section{STRESS RELIEF TREATMENT}

After fabrication, the pressure vessel is given a relatively low temperature $\left(\sim 600^{\circ} \mathrm{C}\right)$ anneal to relieve the stresses in the steel associated with the welding process. Extrapolation of high temperature solubility data and thermodynamic predictions indicate that the solubility of copper in the steel matrix changes relatively rapidly over the temperature range $\left(\sim 575\right.$ to $\left.\sim 650^{\circ} \mathrm{C}\right)$ due to the precipitation of the face centered cubic $\varepsilon$-copper phase on dislocations and grain boundaries. Therefore, the amount of copper remaining in solid solution in the matrix will depend on the copper level in the steel, the time and temperature of the stress relief treatment and the subsequent cooling rate to room temperature. A recent systematic atom probe study has been performed to determine the matrix copper content of a high copper weld $(\mathrm{Fe}-0.29$ at. \% $\mathrm{Cu}$, 
$1.69 \% \mathrm{Mn}, 0.54 \% \mathrm{Ni}, 0.69 \% \mathrm{Si}, 0.25 \% \mathrm{Mo}, 0.08 \% \mathrm{Cr}, 0.38 \% \mathrm{C}, 0.022 \% \mathrm{P}$ and $0.017 \% \mathrm{~S}$ ) subjected to different stress relief temperatures and cooling rates [8]. The results of this study have indicated that both lower stress relief temperatures and slower cooling rates reduce the copper level in the matrix, as shown in Fig. 1. These reductions in the copper level should lead to less embrittlement in the nuclear reactor, as less copper is available to form copper-enriched precipitates during service. Therefore, the stress relief treatment is important in limiting the copper level in the matrix in high copper steels in addition to its primary role in relieving the stresses in the vessel. It should be emphasized that one of the important parameters to ascertain the susceptibility of the steel to embrittlement is the copper level in the matrix prior to exposure in the reactor rather than the bulk copper content of the steel.

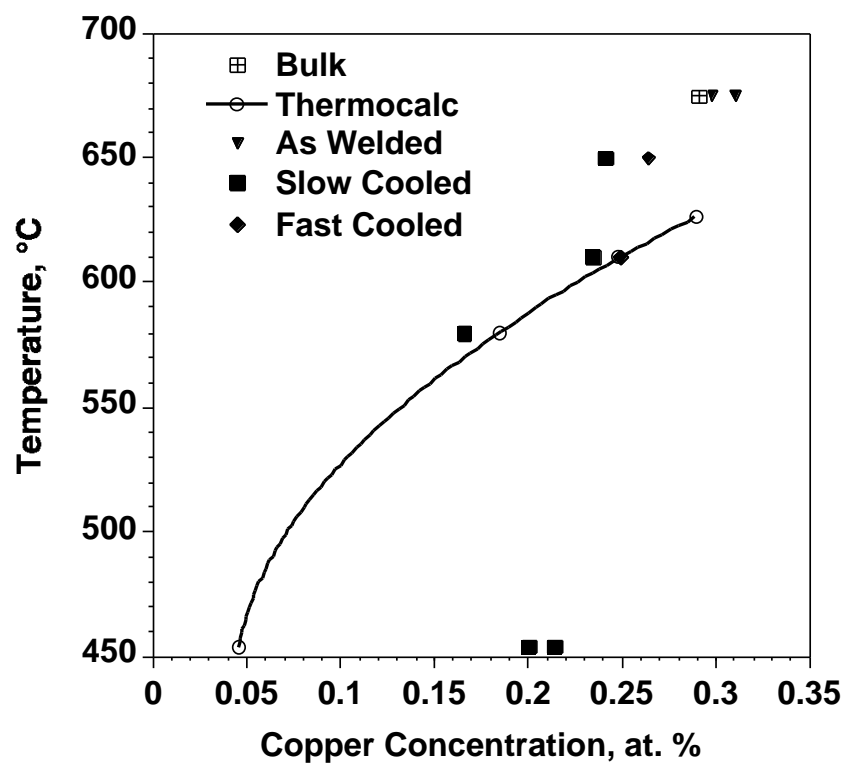

Fig. 1. The predicted and measured copper concentrations of the matrix of a high copper (0.29 at. $\% \mathrm{Cu}$ ) weld after different stress relief treatments (as welded, $24 \mathrm{~h}$ at $650^{\circ} \mathrm{C}, 24 \mathrm{~h}$ at $610^{\circ} \mathrm{C}$, $100 \mathrm{~h}$ at $580^{\circ} \mathrm{C}$ and $24 \mathrm{~h}$ at $610^{\circ} \mathrm{C}$ slow cooled $+168 \mathrm{~h}$ at $\left.454^{\circ} \mathrm{C}\right)$.

\section{MATRIX COMPOSITIONS}

Systematic measurements of the composition of the matrix after exposure to neutron irradiation and annealing treatments have been obtained from several different types of pressure vessel steels [9-12]. These measurements accurately reflect the true solute content of the matrix since the spatial resolution of the atom probe is sufficient to detect and eliminate any contributions from ultra-fine precipitates, clusters and solute segregation. A representative set of data is shown in Fig. 2 for a (WF-70) weld taken from the Midland reactor [10]. This weld was fabricated with the use of copper-coated welding rods and Linde 80 flux. Bulk chemical analyses of this weld have shown that the copper level varied from 0.18 to 0.28 at. \% $\mathrm{Cu}$. As discussed in the previous section, the stress relief treatment $\left(22.5 \mathrm{~h}\right.$ at $\left.607^{\circ} \mathrm{C}\right)$ substantially reduces the copper content of the matrix. Neutron irradiation to a fluence of $1.1 \times 10^{23} \mathrm{n} \mathrm{m}^{-2}(\mathrm{E}>1 \mathrm{MeV})$ further reduces the copper matrix level to a level of $\sim 0.05$ at. $\% \mathrm{Cu}$ and forms a high number density of copper-enriched precipitates in the matrix $[10,11]$. This low copper level has been observed in a 
number of different types of RPV steels. In addition, no copper-enriched precipitates were observed and the copper was found to remain in solid solution in the matrix of some low copper level (0.05-0.06 at. \% Cu) 15Kh2MFA base and 10KhMFT welds after neutron irradiation [12]. The copper level decreases slightly and the copper-enriched precipitates were found to increase in size after a post irradiation anneal of $168 \mathrm{~h}$ at $454^{\circ} \mathrm{C}$. A recent study of an A533B steel after re-irradiation following a similar post irradiation anneal has revealed a further small decrease in the copper level [13]. In contrast, a comparison of unaged and long-term thermally aged $\left(\sim 100,000 \mathrm{~h}\right.$ at $\left.300^{\circ} \mathrm{C}\right) \mathrm{SA}-508$ forging, SA-533B plate and submerged arc weld materials did not reveal any changes in the mechanical properties or the copper level in the matrix [14].

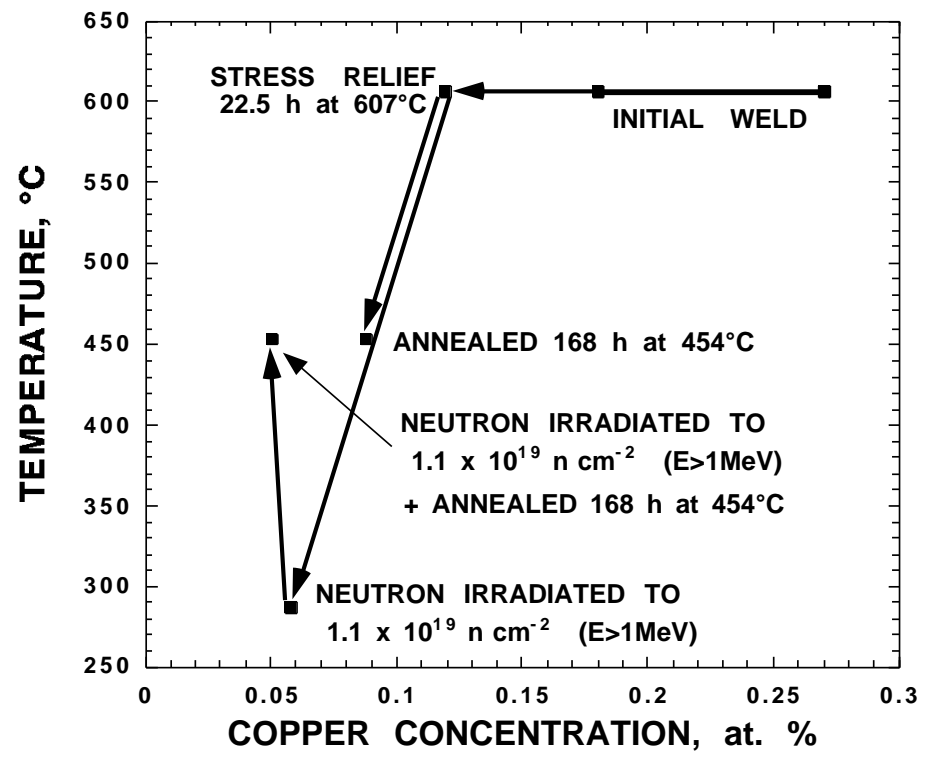

Fig. 2. The copper concentration in the matrix of steel from the Midland pressure vessel after the stress relief treatment, neutron irradiation, annealing for $168 \mathrm{~h}$ at $454^{\circ} \mathrm{C}$, neutron irradiation and annealing for $168 \mathrm{~h}$ at $454^{\circ} \mathrm{C}$.

\section{COPPER-ENRICHED PRECIPITATES}

Excluding the formation of vacancies and other types of point defects, the most prevalent microstructural change that occurs during neutron irradiation of high copper RPV steels is the formation of copper-enriched precipitates. The atom probe has provided significant information as to the nature of these ultra-fine precipitates [5,6,15-17]. A set of atom maps of these copperenriched precipitates for a neutron irradiated RPV steel is shown in Fig. 3. In this type of representation, a sphere is used to represent the position of an individual atom. The presence of the copper-enriched precipitates is indicated by the high local concentration of copper. It is also evident that high concentrations of nickel, manganese and silicon are associated with the high level of copper. The morphology of these precipitates is best described as roughly spherical. The size of these features is generally found to be $\sim 2 \mathrm{~nm}$ in diameter. The composition of the core of these precipitates may be estimated by defining a small volume within the precipitate and counting the number of atoms of each element. Alternatively, composition profiles through the 
center of the precipitate or radial composition profiles emanating from the center of mass of the precipitate may be constructed, as shown in Fig. 4. All these approaches clearly reveal that there is a significant concentration of iron and that there are enrichments of nickel, manganese and silicon in these precipitates. Close examination of the structure of the precipitate-matrix interface indicates that is it not abrupt as would be expected for classical precipitation but diffuse or ramified. Composition profiles also indicate that the nickel and manganese are enriched at the precipitate-matrix interface. Additional examples of the nature of these copper-enriched precipitates after neutron irradiation, annealing and re-irradiation may be found elsewhere [13].

The influence of manganese on the size, number density and composition of the copperenriched precipitates has also been investigated in neutron-irradiated binary and ternary model alloys, as shown in Fig. 5. The number density of the precipitates was found to be an order of magnitude higher and their size smaller in the manganese-containing alloy.

Atom probe data from the French Dampierre 2 vessel indicated that for high doses ( 90 mdpa) and low copper levels $(0.06 \%$ or $0.08 \% \mathrm{Cu})$, well-defined clusters are observed with local copper concentration of less than 1\%, as shown in Figs. 3 and 4 [11]. At high doses and high copper contents, well-defined clusters are observed and can be analyzed in terms of size, composition, and number density. Between these two categories, a third category - a cloud, has been identified. In this case, solute clustering was clearly visible but not sufficiently well defined to be able to determine a diameter or describe them as clusters. Recent atom probe tomography results have also highlighted that the intermediate evolution of the microstructure under irradiation is strongly dependent on the nominal matrix chemistry and neutron dose $[18,19]$.

\section{Dampierre 4}

\section{$5.2 \times 10^{23} \mathrm{n} / \mathrm{m}^{2}$}

Volume $15 \times 15 \times 50 \mathrm{~nm}^{3}$
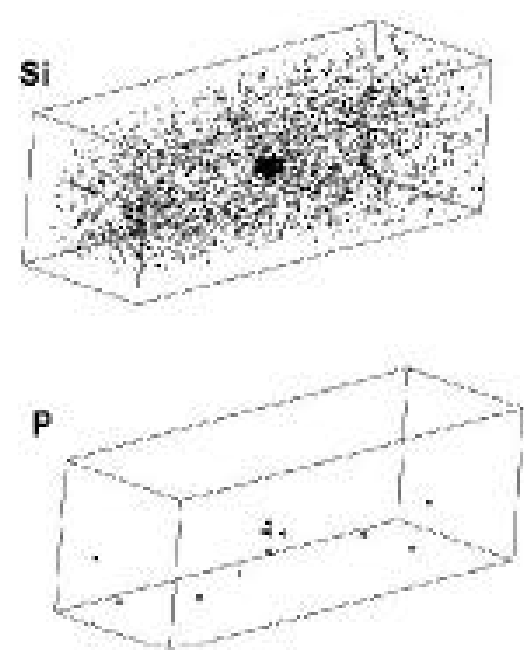
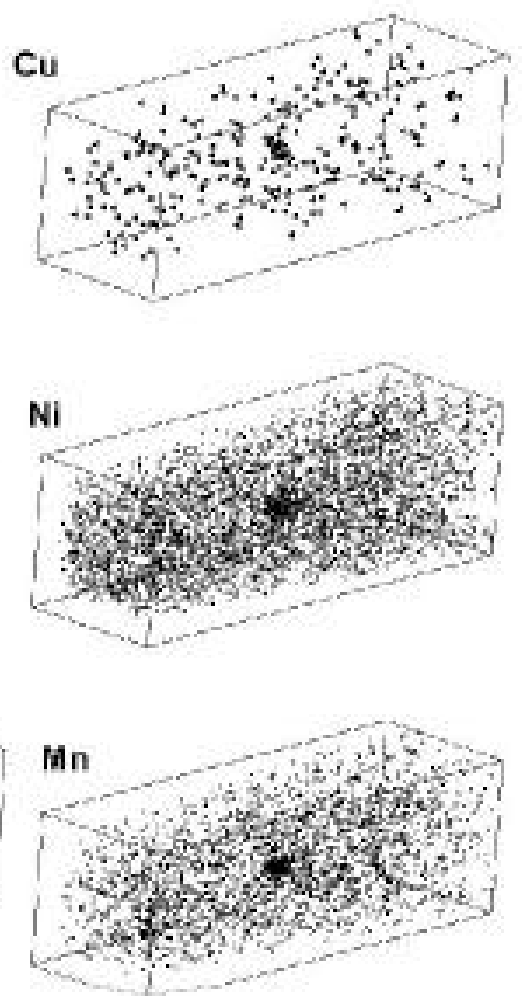

Fig. 3. Atom maps of copper-enriched precipitates in a neutron irradiated RPV steel (base metal of the vessel of French Dampierre 2 reactor, fluence $5.2 \times 10^{23}$ n.m. $m^{-2}$, temperature $290^{\circ} \mathrm{C}$ ). 


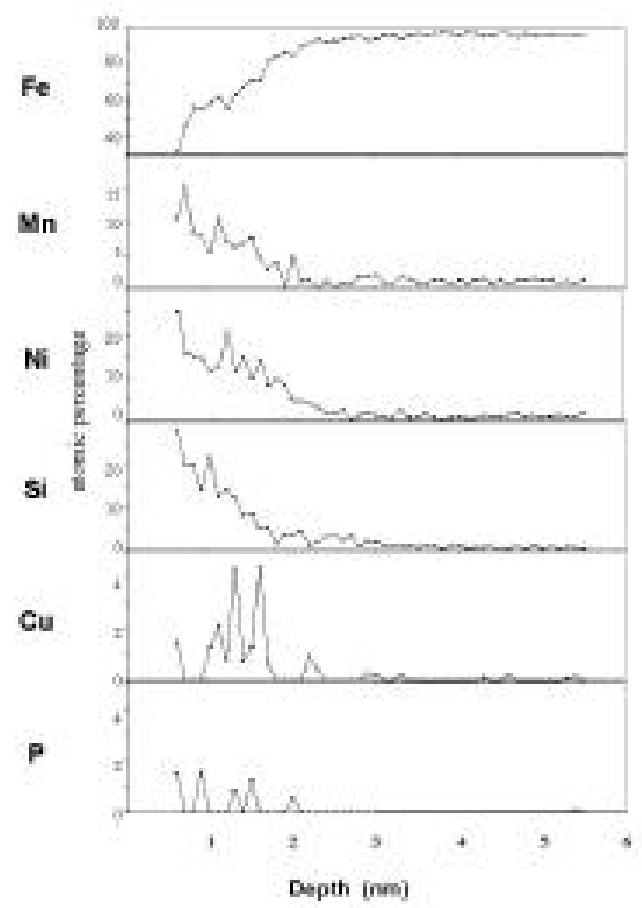

Fig. 4. Radial distribution of solutes from a copper-enriched precipitate (see figure 3).
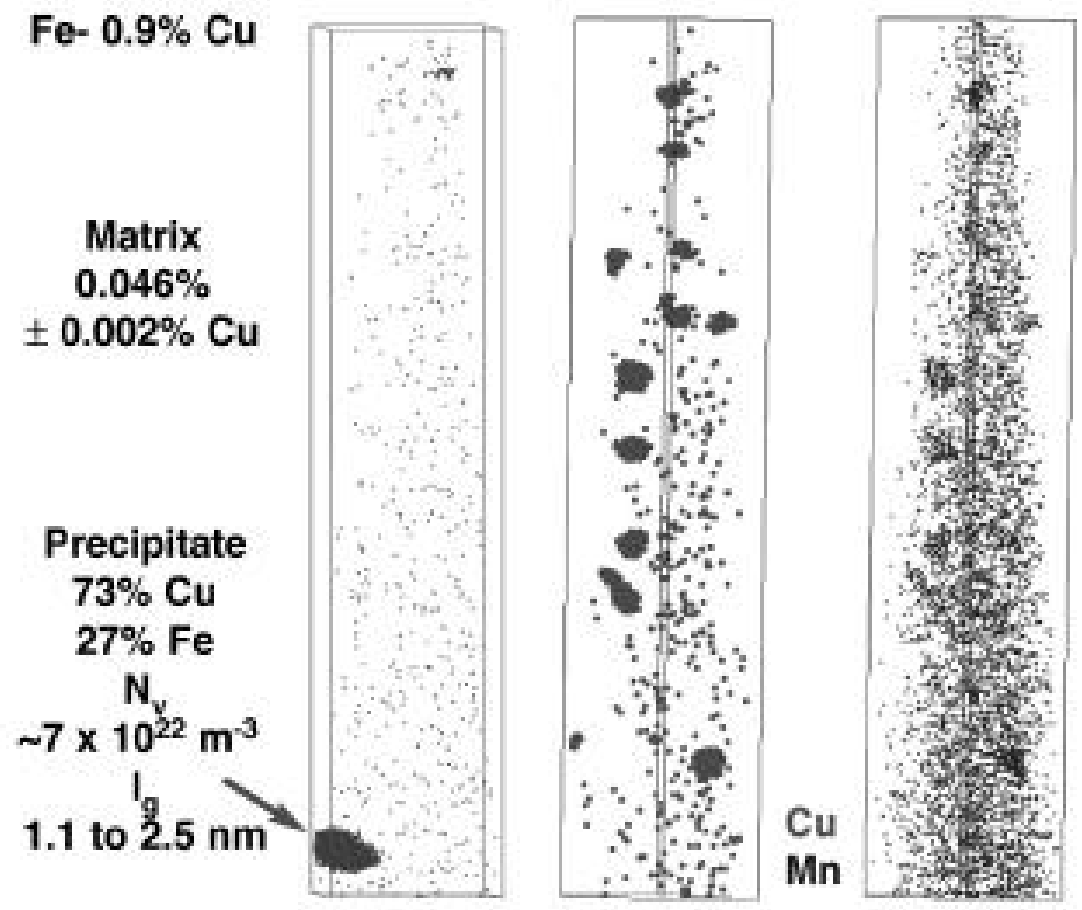

$\mathrm{Fe}-0.9 \% \mathrm{Cu}$

$-1.0 \% \mathrm{Mn}$

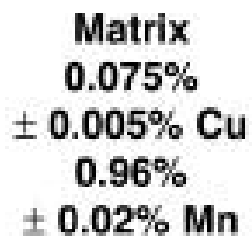

Precipitates

$44 \% \mathrm{Cu}$

$4 \% \mathrm{Mn}$

$52 \% \mathrm{Fe}$

$7 \times 10^{23} \mathrm{~m}^{-3}$

$1.8 \mathrm{gm}$

Fig. 5. Comparison of the distribution of copper-enriched precipitates in neutron irradiated (fluence $\left.1 \times 10^{23} \mathrm{n} \mathrm{m}^{-2}(\mathrm{E}>1 \mathrm{MeV})\right) \mathrm{Fe}-0.9 \% \mathrm{Cu}$ and $\mathrm{Fe}-0.9 \% \mathrm{Cu}-1.0 \% \mathrm{Mn}$ model alloys. 


\section{PHOSPHORUS-ENRICHED REGIONS}

Small phosphorus-enriched regions have been observed in several neutron-irradiated RPV steels and model alloys. A typical example of a phosphorus-enriched region in a submerged arc weld (Fe- 0.27 at. $\% \mathrm{Cu}, 1.58 \% \mathrm{Mn}, 0.57 \% \mathrm{Ni}, 0.34 \% \mathrm{Mo}, 0.27 \% \mathrm{Cr}, 0.58 \% \mathrm{Si}, 0.45 \% \mathrm{C}$, $0.009 \% \mathrm{P}$, and $0.009 \% \mathrm{~S}$.$) that had been neutron irradiated to a fluence of 2 \times 10^{23} \mathrm{n} \mathrm{m}^{-2}(\mathrm{E}>$ $1 \mathrm{MeV}$ ) and annealed for $0.5 \mathrm{~h}$ at $454^{\circ} \mathrm{C}$ is shown in Fig. 6. This phosphorus-enriched region contained 192 phosphorus atoms, had a radius of gyration of $1.8 \mathrm{~nm}$ and was very diffuse in nature. No copper atoms were found to be associated with this feature. Phosphorus is often found to be present at precipitate-matrix interfaces and at boundaries.

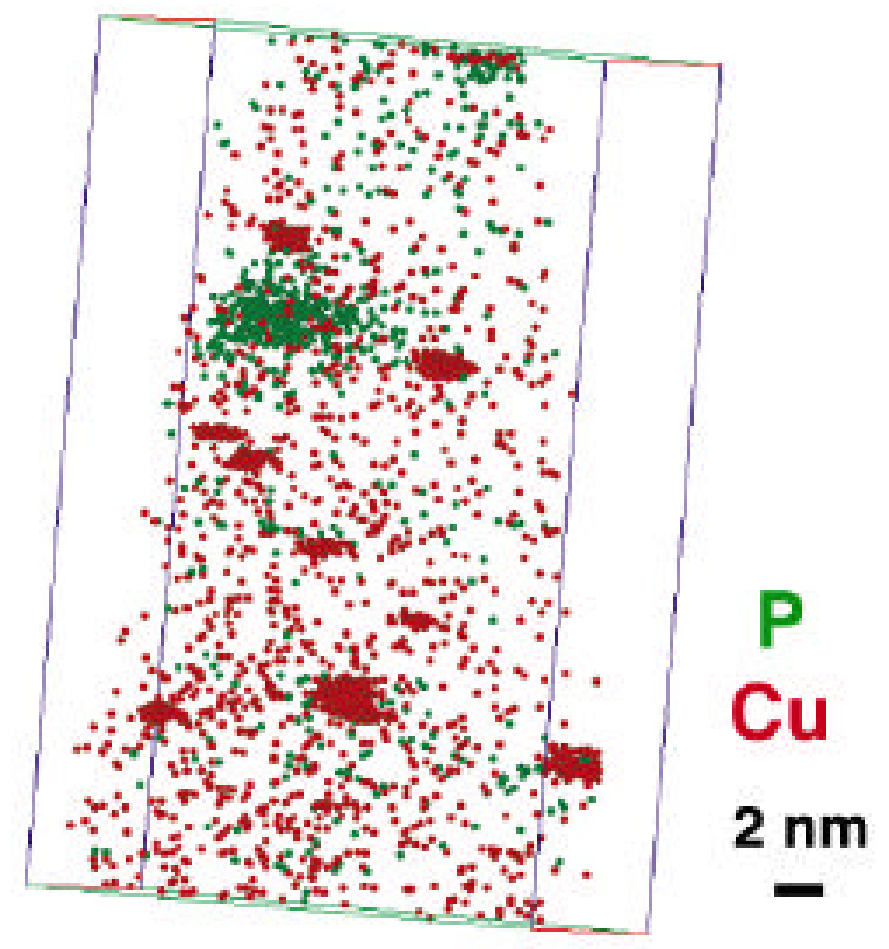

Fig. 6. Atom map of phosphorus and copper-enriched precipitates in a submerged arc weld that was neutron irradiated to a fluence of $2 \times 10^{23} \mathrm{n} \mathrm{m}^{-2}(\mathrm{E}>1 \mathrm{MeV})$ and annealed for $0.5 \mathrm{~h}$ at $454^{\circ} \mathrm{C}$.

\section{SOLUTE SEGREGATION TO DISLOCATIONS}

Recent atom probe tomography studies have revealed that solute segregation to dislocations is an important process in neutron irradiated pressure vessel steels. An atom map showing phosphorus segregation to a dislocation in a neutron-irradiated pressure vessel steel is shown in Fig. 7. This example was the base metal of the inside layer of the Novovoronezh Unit 2 VVER 440 vessel that was irradiated to a fluence of $6.5 \times 10^{23} \mathrm{n} \mathrm{m}^{-2}(\mathrm{E}>0.5 \mathrm{MeV})$ with a flux of $12 \times 10^{14}$ $\mathrm{n} \mathrm{m}^{-2} \mathrm{~s}^{-1}$ at a service temperature of $275^{\circ} \mathrm{C}$. In this material, the copper depletion measured after neutron irradiation is consistent with the observation of $\mathrm{Cu}-\mathrm{Ni}-\mathrm{Mn}-\mathrm{Mn}-\mathrm{P}$-enriched clusters (as described in the previous section). The linear morphology of the phosphorus distribution is 
characteristic of segregation to a dislocation. The local number density of dislocations was estimated to be $4 \times 10^{10} \mathrm{~cm}^{-2}$. This high local value is due to a non-homogeneous distribution of the dislocations. The solute concentrations in the core of the dislocations have been estimated and are reported in Table 1. Some copper-enriched clusters are localized on the core of dislocations (heterogeneous formation), as shown in Fig 7. Copper-enriched clusters are also observed in the matrix (homogeneous formation). A comparison of the size and composition of the precipitates observed on dislocations and in the matrix is given in Table 2 . The particles near dislocations are more enriched in copper than those in the matrix. It is also evident that particles with the highest copper content are not necessarily the largest.

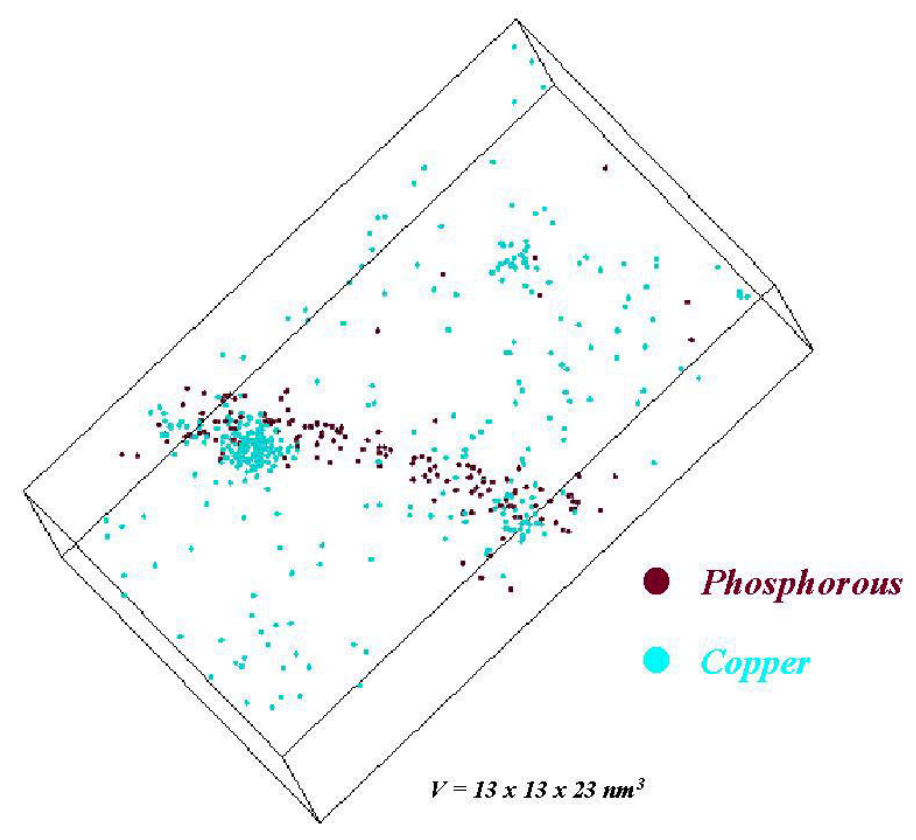

Fig. 7. Phosphorus segregation and a copper-enriched precipitate on a dislocation in the base metal of the inside layer of the Novovoronezh Unit 2 VVER 440 vessel. The linear morphology of the distribution of phosphorus atoms is characteristic of the presence of a dislocation. Only $\mathrm{Cu}$ and $P$ atoms are shown. Irradiation conditions are a fluence of $6.5 \times 10^{23} \mathrm{n} \mathrm{m}^{-2}(E>0.5 \mathrm{MeV})$ (flux: $12 \times 10^{14} \mathrm{n} \mathrm{m}^{-2} \mathrm{~s}^{-1}$ ) and at a temperature of $275^{\circ} \mathrm{C}$.

Table 1: Solute concentrations at the core of dislocations in atomic percent. The two data sets are representative of dislocations with or without carbon and vanadium segregation.

\begin{tabular}{|c|c|c|c|c|c|c|c|c|}
\hline $\mathrm{Fe}$ & $\mathrm{Cu}$ & $\mathrm{Mn}$ & $\mathrm{Ni}$ & $\mathrm{Si}$ & $\mathrm{Cr}$ & $\mathrm{P}$ & $\mathrm{V}$ & $\mathrm{C}$ \\
\hline $84.3 \pm 2.9$ & $0.9 \pm 0.8$ & $4.5 \pm 1.6$ & $1.9 \pm 1.1$ & $3.0 \pm 1.3$ & $1.9 \pm 1.1$ & $3.4 \pm 1.4$ & - & - \\
$83.7 \pm 2.2$ & $2.3 \pm 0.9$ & $3.3 \pm 1.1$ & $1.3 \pm 0.7$ & $2.2 \pm 0.9$ & $2.2 \pm 0.9$ & $2.4 \pm 0.9$ & $2.0 \pm 0.8$ & $0.6 \pm 0.5$ \\
\hline
\end{tabular}


Table 2: Size (radius) and copper content of the particles observed in the weld irradiated metal. Two types of particles are considered: near dislocations or isolated in the matrix.

\begin{tabular}{|c|c|c|c|c|c|c|c|c|c|}
\hline & \multicolumn{4}{|c|}{ On dislocations } & \multicolumn{5}{c|}{ In the matrix } \\
\hline Radius, $\mathrm{nm}$ & 1 & 0.6 & 0.9 & 0.5 & 1 & 1 & 1 & 0.9 & 0.8 \\
\hline at. $\% \mathrm{Cu}$ & 34 & 21 & 31 & 56 & 13 & 38 & 8 & 20 & 18 \\
\hline $2 \sigma$ & 5 & 7 & 5 & 16 & 4 & 7 & 4 & 6 & 6 \\
\hline
\end{tabular}

Significant increases were found in the ductile-to-brittle transition temperature (DBTT), yield and ultimate tensile strengths and reductions were found in the elongation and reduction in area in both low copper $(\sim 0.06 \mathrm{a}$. \% Cu) 15Kh2MFA base and 10KhMFT weld surveillance specimens after neutron irradiation at $270^{\circ} \mathrm{C}$ for 10 years to a fluence of $1.0 \times 10^{25} \mathrm{~m}^{-2}(\mathrm{E}>$ $0.5 \mathrm{MeV})$ for the base material and at $275{ }^{\circ} \mathrm{C}$ for 5 years to a fluence of $5.2 \times 10^{24} \mathrm{~m}^{-2}(\mathrm{E}>0.5$ $\mathrm{MeV}$ ) for the weld, as shown in Table 3 [12]. These changes were not observed in the same material thermally annealed for similar times at $295^{\circ} \mathrm{C}$. It was experimentally observed that these changes in mechanical properties correlate with the presence of manganese-, silicon-, copper-, phosphorus- and carbon-decorated dislocations and other features in the matrix of the neutron irradiated base and weld materials, as shown in Fig. 8. The solute atmospheres extended for $\sim 3$ to $4 \mathrm{~nm}$ suggesting that the segregation was associated with the stress field around the dislocation (i.e., similar to a Cottrell atmosphere). Similar solute segregation has also been observed in a weld $(\mathrm{Fe}-0.27$ at. $\% \mathrm{Cu}, 1.58 \% \mathrm{Mn}, 0.57 \% \mathrm{Ni}, 0.34 \% \mathrm{Mo}, 0.27 \% \mathrm{Cr}, 0.98 \% \mathrm{Si}$, $0.003 \% \mathrm{~V}, 0.45 \% \mathrm{C}, 0.009 \% \mathrm{P}$, and $0.009 \% \mathrm{~S}$ ) that was neutron irradiated to a fluence of $1.8 \mathrm{x}$ $10^{23} \mathrm{n} \mathrm{m}^{-2}(\mathrm{E}>1 \mathrm{MeV})$, annealed for $168 \mathrm{~h}$ at $454^{\circ} \mathrm{C}$, and re-irradiated to an addition fluence of $0.8 \times 10^{23} \mathrm{n} \mathrm{m}^{-2}(\mathrm{E}>1 \mathrm{MeV})$ [13]. All these solute-enriched regions will significantly impede the motion of dislocations and thereby account for substantial changes in the mechanical properties.

Table 3. Summary of the mechanical properties of the low copper $(\sim 0.06 \mathrm{a} . \% \mathrm{Cu}) 15 \mathrm{Kh} 2 \mathrm{MFA}$ base and 10KhMFT weld surveillance specimens for the unirradiated, thermally aged and neutron-irradiated conditions [12] The elongation $\mathrm{A}_{10}$ is given.

\begin{tabular}{|c|c|c|c|c|c|c|c|c|c|c|}
\hline \multirow[t]{2}{*}{ Material } & \multirow[t]{2}{*}{ State } & \multirow{2}{*}{$\begin{array}{l}\text { DBTT } \\
{ }^{\circ} \mathrm{C} \\
\end{array}$} & \multicolumn{2}{|c|}{$\begin{array}{c}\text { Yield } \\
\text { strength, } \\
\mathrm{MPa}\end{array}$} & \multicolumn{2}{|c|}{$\begin{array}{c}\text { Ultimate } \\
\text { Tensile } \\
\text { Strength, MPa }\end{array}$} & \multicolumn{2}{|c|}{$\begin{array}{c}\text { Elongation, } \\
\%\end{array}$} & \multicolumn{2}{|c|}{$\begin{array}{c}\text { Reduction in } \\
\text { area, } \%\end{array}$} \\
\hline & & & $25^{\circ} \mathrm{C}$ & $265^{\circ} \mathrm{C}$ & $25^{\vee} \mathrm{C}$ & $265^{\circ} \mathrm{C}$ & $25^{\circ} \mathrm{C}$ & $265^{\circ} \mathrm{C}$ & $25^{\circ} \mathrm{C}$ & $265^{\circ} \mathrm{C}$ \\
\hline Base & unirradiated & -49 & 527 & 458 & 639 & 535 & 13.8 & 10.0 & 81 & 77 \\
\hline Base & $\begin{array}{c}\text { irradiated } \\
10 \text { years }\end{array}$ & 141 & 879 & 760 & 880 & 779 & 2.2 & 4.2 & 5 & 27 \\
\hline Base & $\begin{array}{c}\text { aged } 10 \\
\text { years }\end{array}$ & -70 & 526 & 470 & 631 & 534 & 14.7 & 9.9 & 79 & 78 \\
\hline Weld & unirradiated & 7 & 475 & 377 & 600 & 491 & 17.9 & 13.2 & 72 & 71 \\
\hline Weld & $\begin{array}{c}\text { Irradiated } \\
5 \text { years }\end{array}$ & 123 & 750 & 646 & 761 & 708 & 6.4 & 4.9 & 16 & 16 \\
\hline Weld & aged 5 years & 11 & 483 & 407 & 593 & 514 & 15.6 & 12.7 & 70.4 & 67.6 \\
\hline
\end{tabular}



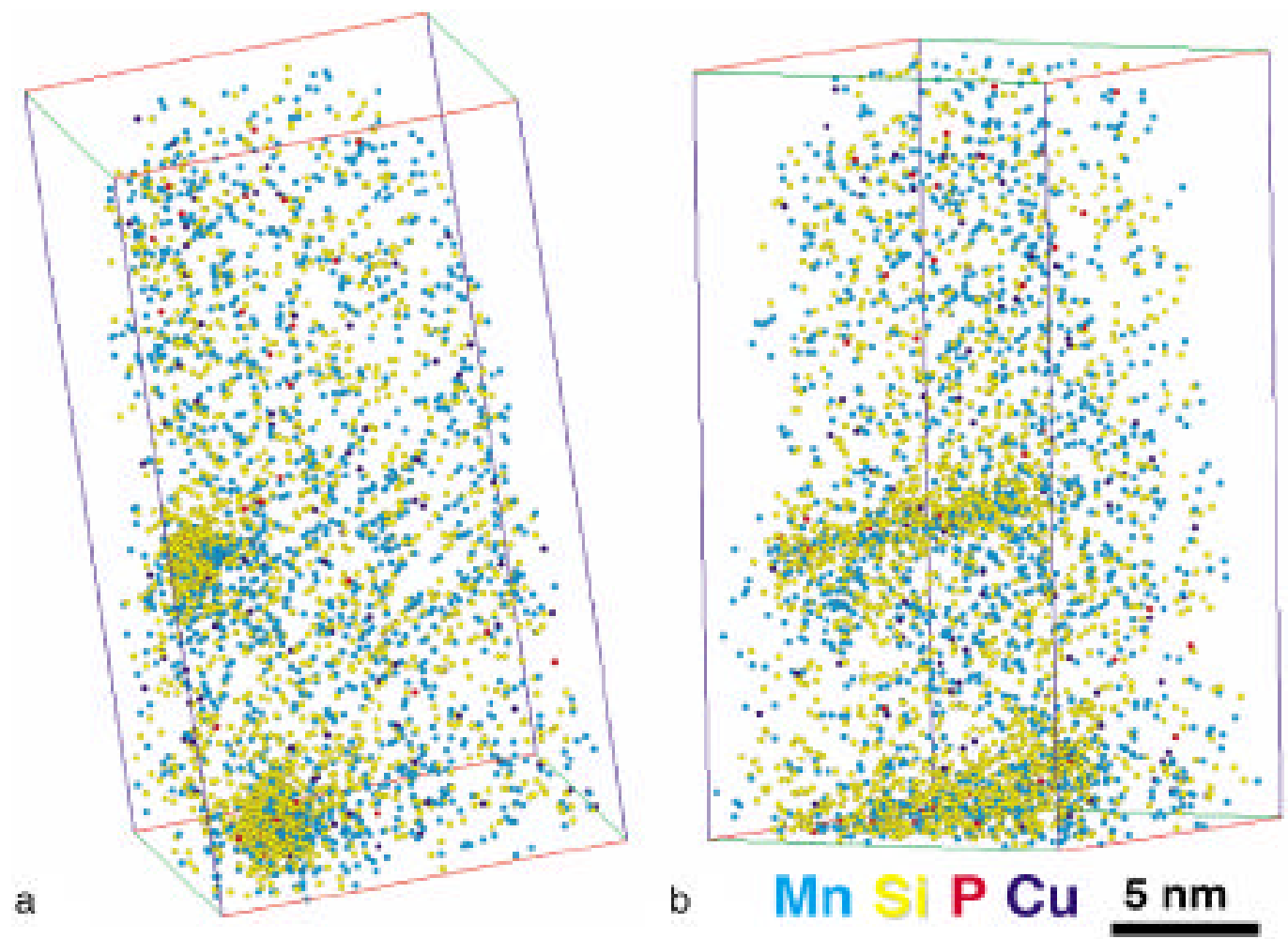

Fig. 8. Segregation of manganese, silicon, phosphorus and copper to dislocations in a neutron irradiated low copper (0.06 at. \% Cu) VVER 440 weld. a) end on view, b) side view. [12]

\section{SOLUTE SEGREGATION TO BOUNDARIES}

Solute segregation to lath and grain boundaries is also common in both unirradiated and neutron-irradiated materials. It has been experimentally determined that the McLean model of equilibrium segregation can predict the level of phosphorus segregation in the unirradiated material $[20,21]$. These predictions have also indicated that annealing the high phosphorus steels dramatically increases the phosphorus level at the boundaries. A set of atom maps containing a lath boundary in a neutron irradiated VVER 440 pressure vessel steel weld containing $\mathrm{Fe}-1.71$ at. $\% \mathrm{Cr}, 0.95 \% \mathrm{Mn}, 0.69 \% \mathrm{Si}, 0.37 \% \mathrm{Mo}, 0.20 \% \mathrm{~V}, 0.14 \% \mathrm{Ni}, 0.11 \% \mathrm{Cu}, 0.23 \% \mathrm{C}$ and $0.058 \%$ $\mathrm{P}$ is shown in Fig. 9. It is evident from this atom map that solute segregation of phosphorus, manganese and molybdenum to the plane of the boundary has occurred. The level of segregation may be estimated from these data in terms of the Gibbsian interfacial excess from the number of solute atoms at the boundary, estimating the matrix concentration and the interfacial area [3]. In this pressure vessel steel weld, the Gibbsian interfacial excesses of the solutes were determined to be $\Gamma_{\mathrm{P}}=2.5 \times 10^{-18}, \Gamma_{\mathrm{Mn}}=3.8 \times 10^{-18}, \Gamma_{\mathrm{Mo}}=2.0 \times 10^{-18}$ and $\Gamma_{\mathrm{C}}=1.2 \times 10^{-18}$ atoms $\mathrm{m}^{-2}$. This set of data also includes three copper precipitates close to the boundary, as shown in Fig. 9. 

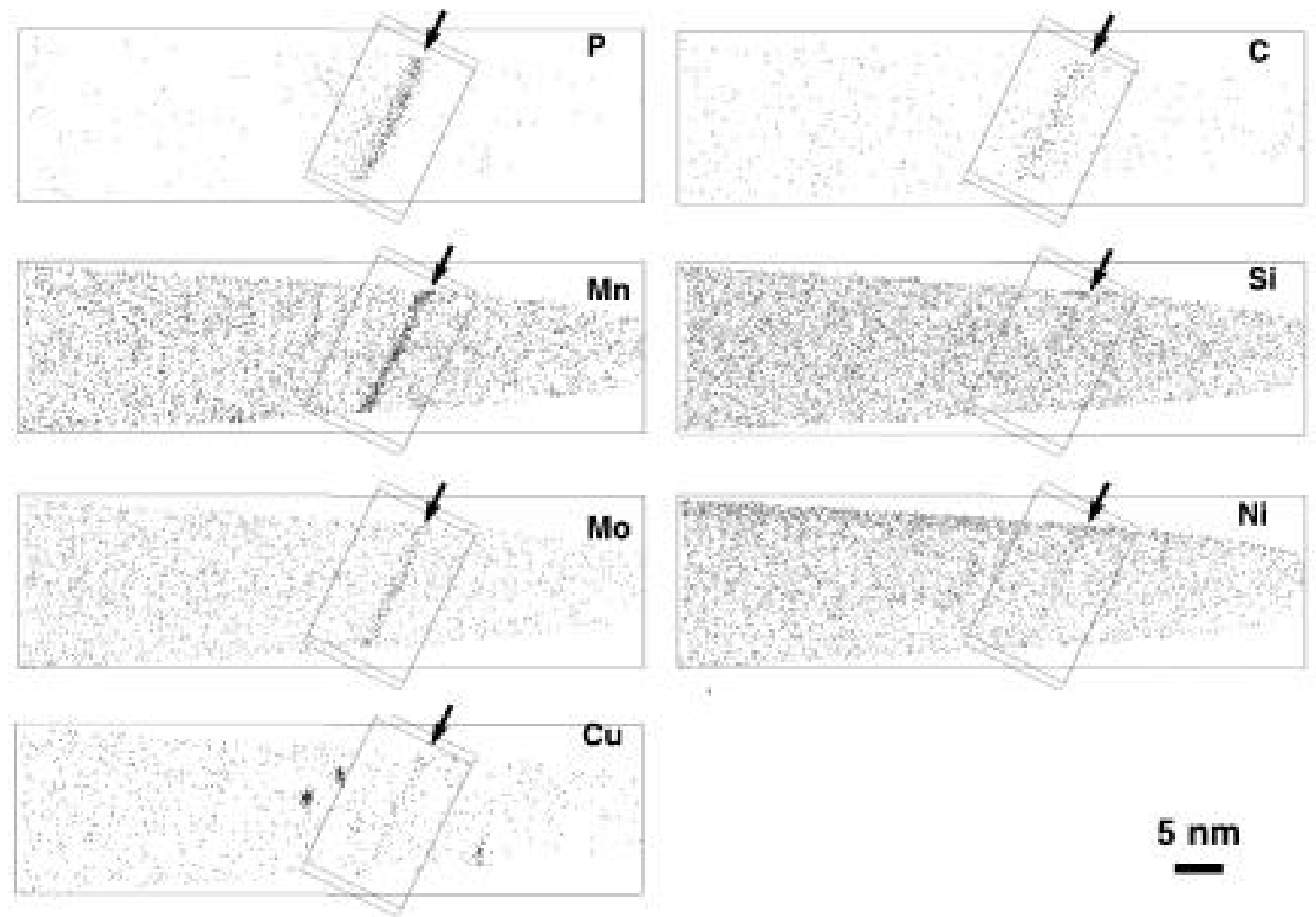

Fig. 9. Solute segregation of phosphorus, manganese, molybdenum and carbon to a lath boundary in a neutron irradiated high phosphorus VVER 440 submerged arc weld.

\section{CONCLUSIONS}

Atom probe tomography has revealed that the microstructure of pressure vessel steels is complex and that many different microstructural changes occur during neutron irradiation. These changes include the formation of copper-enriched precipitates, phosphorus-enriched features, and solute segregation to dislocations, precipitate-matrix interfaces and grain boundaries.

\section{ACKNOWLEDGEMENTS}

This research at the Oak Ridge National Laboratory SHaRE User Facility was sponsored by the Division of Materials Sciences and Engineering, U.S. Department of Energy, under Contract DE-AC05-000R22725 with UT-Battelle, LLC, by the Office of Nuclear Regulatory Research, U. S. Nuclear Regulatory Commission under inter-agency agreement DOE 1886-N695-3W with the U. S. Department of Energy, and through the SHaRE Program under contract DE-AC0576OR00033 with Oak Ridge Associated Universities. Research at the Groupe de Physique des Matériaux was sponsored by Electricité de France, Département Etude des Matériaux, (Centre de recherche des Renardières). The authors would like to thank Prof. G. R. Odette of the University of California - Santa Barbara for supplying the model alloys. 


\section{REFERENCES}

1. M.K. Miller and G. D. W. Smith, Atom Probe Microanalysis, Principles and Applications to Materials Problems, 1989, Materials Research Society, Pittsburgh PA.

2. M. K. Miller, A. Cerezo, M. G. Hetherington and G. D. W. Smith, Atom Probe Field Ion Microscopy, 1996, Oxford University Press, Oxford, UK.

3. M. K. Miller, Atom Probe Tomography, 2000, Kluwer Academic/Plenum Publishers, New York, NY.

4. M. K. Miller, J. Microscopy, 192, 1 (1997).

5. M. K. Miller, M. G. Hetherington and M. G. Burke, Metall. Trans., 20A, 2651 (1989).

6. M. K. Miller, P. Pareige and M. G. Burke, Materials Characterization, 44, 235 (1999).

7. P. Pareige, Etude a La Sonde Atomique de L'Evolution Microstructurale Sous Irradiation D'Alliages Ferritiques FeCu et D'Aciers de Cuve de Reacteurs Nucleaires, Ph. D. Thesis, University of Rouen, Rouen, France, 1994.

8. M. K. Miller, S. S. Babu, M. A. Sokolov, R. K. Nanstad and S. K. Iskander, Mater. Sci. Eng. $A$, in press.

9. P. Pareige, R. E. Stoller, K. F. Russell and M. K. Miller, J. Nucl. Mater., 249, 165 (1997).

10. M. K. Miller and K. F. Russell, J. Nucl. Mater., 250, 223 (1997).

11. P. Auger, P. Pareige, S. Welzel, and J.C. Van Duysen, J. Nucl. Mater., 280, 331 (2000).

12. M. K. Miller, K. F. Russell, J. Kocik and E. Keilova, J. Nucl. Mater., 282, 83 (2000).

13. M. K. Miller, K. F. Russell and P. Pareige, these proceedings.

14. P. Pareige, K. F. Russell, R. E. Stoller and M. K. Miller, J. Nucl. Mater., 250, 176 (1997).

15. P. Pareige and M. K. Miller, Appl. Surf. Sci., 94/95, 370 (1996).

16. P. Pareige, J. C. Van Duysen, P. Auger, Appl. Surf. Sci., 67, 342 (1993).

17. P. Auger, P. Pareige, M. Akamatsu and J.C. Van Duysen, J. Nucl. Mater., 211, 194 (1994).

18. J. M. Hyde, D. Ellis, C. A. English and T. J. Williams, "Microstructural evolution in high nickel submerged arc weld," 20th Int. Conf. Effects of Radiation on Materials, ASTM STP 1405, eds. S. T. Rosinski, M.L. Grossbeck, T. R. Allen and A. S. Kumar, American Society for Testing and Materials, West Conshohocken, PA, 2002.

19. J. M. Hyde and C. A. English, these proceedings.

20. M. K. Miller and K. F. Russell, Appl. Surf. Sci., 94/95, 378 (1996).

21. D. McLean, Grain Boundaries in Metals, 1957, Oxford University Press, London, p. 116. 